\title{
Design of Hand Movement based Smart Automation System
}

\author{
B. Ponkarthika, E. Kaliappan, V. Vijeesh, G Vignesh
}

\begin{abstract}
There are millions deaf people in the world and around many people in India who are affected by ALS and paralysis, they face difficulty in communicating with others. Therefore in this paper we propose a system that converts simple gesture to speech and also use these gesture to control the home appliances he project will be in the form of glove which makes it handy and reliable. It uses flex sensors for gesture recognition and TTS module for the gesture to speech feature which makes it slender and much viable.
\end{abstract}

Keywords: Automation, Flex sensors, Gesture recognition, Gesture to speech

\section{INTRODUCTION}

Communication plays an important role in a person's life, but there are people in the world who find it difficult to communicate with others due to their disabilities. The previous versions of this project use smart-devices like smartphones and camera for gesture recognition which makes it impractical. The usage of these devices makes it bulky, less portable and immoderate. These versions were very complex due to which the end users faced difficulties using it. Our project aims at reducing the communication barrier faced by these people. The project will be in the form of glove which makes it handy and reliable. It uses flex sensors for gesture recognition and TTS module for the gesture to speech feature which makes it slender and much viable. For each gesture, a phrase will be encoded. When a person wants to speak that phrase he/she can simply perform the gesture to make the glove speak using a TTS module. This also helps deaf people understand what the other person is saying with the help of speech to text conversion using Google AI. The automation division of the project uses gestures to toggle home appliances so that people with disabilities. The project further can be developed into a sign language translator for more efficient communication of deaf and mute people.

\section{LITERATURE REVIEW}

This paper proposed a gesture based system that recreates a word when a gesture is made. This system uses a smartphone to convert the word to speech [1].Flex sensors for gesture recognition and smartphone for gesture to speech conversion [2]. The authors of the system created a real-time sign language system that translates signs made by the user

Revised Manuscript Received on 14 August, 2019.

B.Ponkarthika, EEE department, Easwari Engineering College, Chennai, Tamil nadu, India.(Email: karthikalai57@gmail.com)

Dr.E.Kaliappan, EEE department, Easwari Engineering College, Chennai, Tamil nadu,India.(Email: ekn.eee@gmail.com)

V.Vijeesh, EEE department, Easwari Engineering College, Chennai, Tamil nadu,India. (Email: vijeesh.vj158@gmail.com)

G.Vignesh, EEE department, Easwari Engineering College, Chennai, Tamil nadu,India. (Email: vignesh.g@eec.srmrmp.edu.in) to speech. An environment is created where a deaf person can send a message to normal person further the message will be converted to speech at the normal person's side [3].

A gesture based home automation system is created that uses camera to recognize the gestures made by the user to toggle the home appliances on and off [4]. A system that uses Bluetooth for automation. The use of Bluetooth is very advantageous because it consumes less power compared to any other communication method. An array of capacitive sensors that recognizes the gestures at any part of the body and send this data to the computer over Bluetooth to control the home appliances. [5].

\section{PROPOSED METHOD}
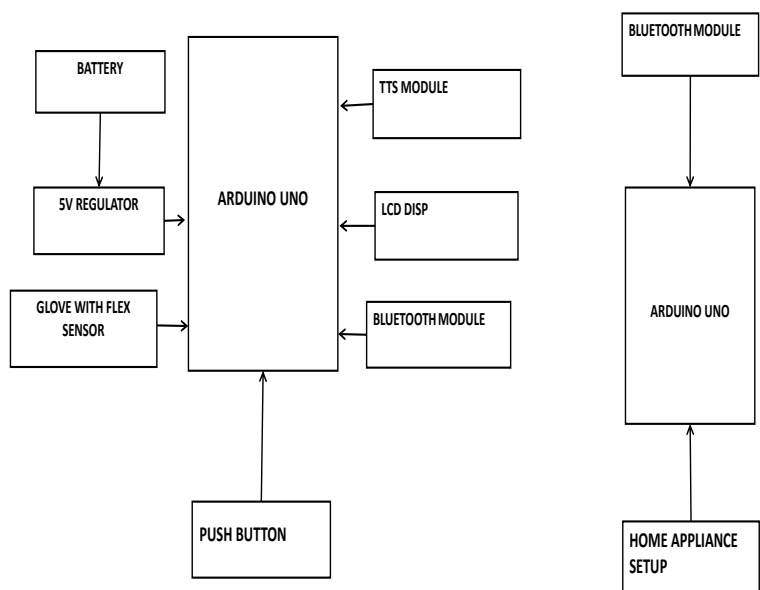

Fig.1.Block Diagram of the system

A system is proposed that converts the gesture from fingers to speech each gesture is encoded with a text.so when a gesture is made the text is converted to speech using TTS module. The glove also have an automation mode that used to control the home appliances remotely using gestures over Bluetooth communication. For each gesture, a phrase will be encoded. When a person wants to speak that phrase he/she can simply perform the gesture to make the glove speak using a TTS module. This also helps deaf people understand.

The aim is to build a low cost solution. The main issues with the previous systems were it needed an internet connection as well as a smart device like a camera or smartphone. This made the system bulky and impractical in countries like India. So we came up with a solution to solve these problems. 


\section{A. HARDWARE IMPLEMENTATION}

A glove is designed that consists of flex sensors that convert gestures to resistance values. There are five sensor of 2.2 inch for each finger so for each gesture a text will be encoded to it.so when a gesture is made the text encoded will be converted to speech using TTS module. There is push button that when pressed switches to automation mode the Bluetooth in the glove connects to the Bluetooth in the automation part. So when a gesture is made it toggle respective relay.

ARDUINO UNO: It is a microcontroller board that is built around the microcontroller ATmega 328p which is 8bit processor. This is the heart of the project and is used to control the whole project. This is an open source platform is programmed using Arduino IDE. The works with 9 volt power or even with 10 to 20 volt supply.

FLEX SENSOR: It is a type of resistor that is flexible and can be easily bent. The flex sensor has a nominal resistance. When bent the resistance starts to increase. There are 2 types of flex sensor based on sizes $2.2 \mathrm{inch}$ and $4.5 \mathrm{inch}$. The output of the flex sensor is also in form of resistance. To extract this output a voltage divider is built using the flex sensor and another resistor.

HC-05 MODULE: This is a master/slave Bluetooth module that is built for Arduino and other microcontrollers. This uses SPI and I2C protocol for communication with the microcontroller. The default baud rate of this module is 9600 . This requires 3.3 volts as its power supply.

TEXT TO SPEECH MODULE: This is a module that converts text to computerized speech. This works based on simple English phonemes this uses UART present in the Arduino to communicate with the controller. The module consists of 2 ports, one for headphone jack and another for speaker which acts as output device for the module

4-CHANNEL RELAY: These are electromagnetic devices that are used to toggle the appliances using microcontroller. The microcontroller output charges the coil in the relay that pulls the thongs to switch on the device. The relay has 2 modes normally open and normally closed. When in normally open mode the switch will be open initially. In normally closed mode the relay will initially be closed.

LCD: Liquid Crystal Display screen is an electronic display module and find a wide range of applications. A $16 \times 2$ LCD display is very basic module and is very commonly used in various devices and circuits. LCDs are economical; easily programmable, have no limitation of displaying. A 16x2 LCD means it can display 16 characters per line and there are 2 such lines. In this LCD each character is displayed in $5 \times 7$ pixel matrix. This LCD has two registers, namely, Command and Data. The command register stores the command instructions given to the LCD.

BATTERY: This is an electrochemical device that can store electrical energy and reproduce it. There are various type of batteries for example: Lithum-ion, Ni-Cd, Lead-acid etc. In this project we use $9 \mathrm{v}$ batteries made up of $\mathrm{Ni}-\mathrm{Cd}$.

\section{B. SOFTWARE IMPLEMENTATION}

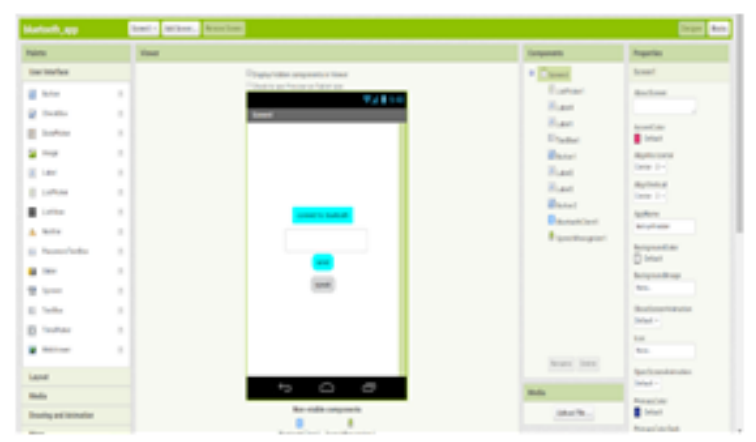

Fig.2. UI of the application

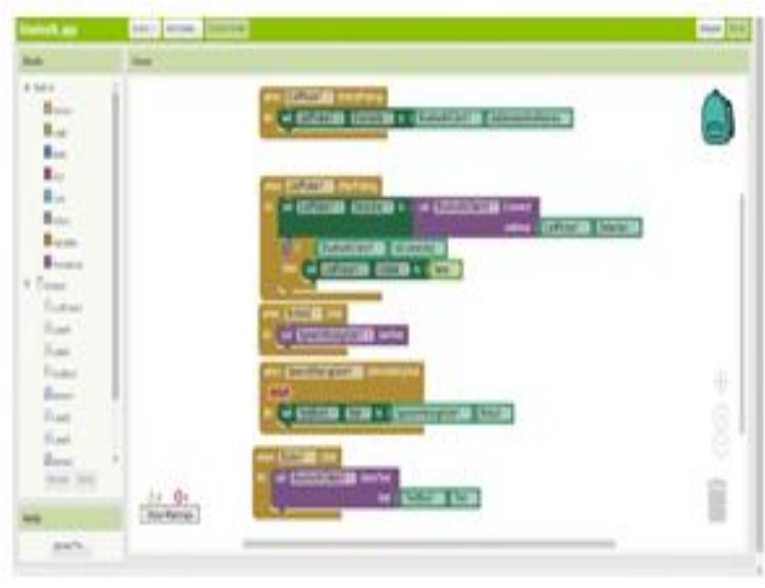

Fig.3. Backend of the application

An android application was developed using MIT APP INVENTOR. This application converts the speech of the user to its equivalent text using Google AI. The application first searches for the Bluetooth connection so it should be manually connected to the Bluetooth present in the glove. Once the Bluetooth is connected the user can send the data seamlessly by pressing the send button. The text sent will appear on the LCD present in the glove. Figure 2 is the User interface of the android application that will be present once opened. Figure 3 is the backend programming of the application.

The microcontroller board we used is Arduino Uno this is programmed using Arduino IDE. The system that we created is programmed using Arduino IDE which was built based on C-programming language which makes it easy to use. This is an open source platform that makes it even more user-friendly. The Arduino IDE employs the program Arduino to convert the executable code into a text file in hexadecimal encoding that is loaded into the Arduino board by a loader program in the board's firmware.

The microcontroller is programmed such a way that it forms a serial communication with both TTS module as well as Bluetooth module. The microcontroller fetches the analog values from the flex sensors and checks if it crosses the threshold value. If the threshold value is crossed the Microcontroller sends serial data to the TTS module for text to speech conversion.

For the Automation mode a push button is provided when 
pressed switches to automation mode. The Bluetooth in the glove pairs with the one is automation system. This again checks for the threshold value. When the threshold is crossed, the Bluetooth module send a unique character to the Bluetooth module in the Automation system. The microcontroller of the automation system toggles the respective relays.

The speech to text conversion acts parallel when the Bluetooth of the phone is connected to Bluetooth of the glove. So when the speech is converted to text in the phone. The text will be transmitted to the glove which will further will be displayed on the LCD.

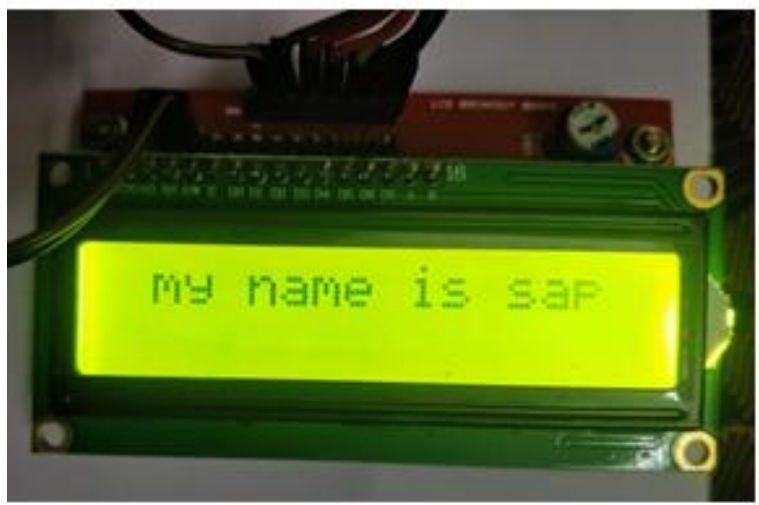

Fig.4. Recepition of text
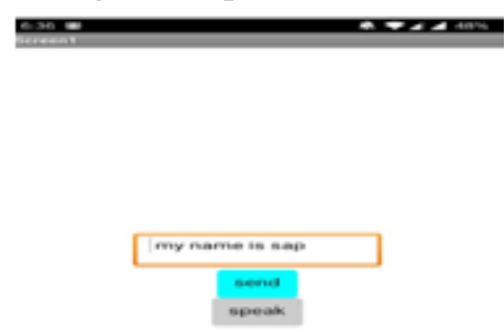

The above figures is the reception of the text and transmission of the text respectively. The transmission the text takes place from the android application. When the Bluetooth of the phone is connected to the Bluetooth of the glove. The user can speak from the application. The application converts the speech into text using Google AI. Once the user press the send button the text will be serially transmitted the gloves Bluetooth where the microcontroller fetches the text and displays it on the LCD.

\section{RESULTS AND DISCUSSION}

\section{GESTURE BASED AUTOMATION}

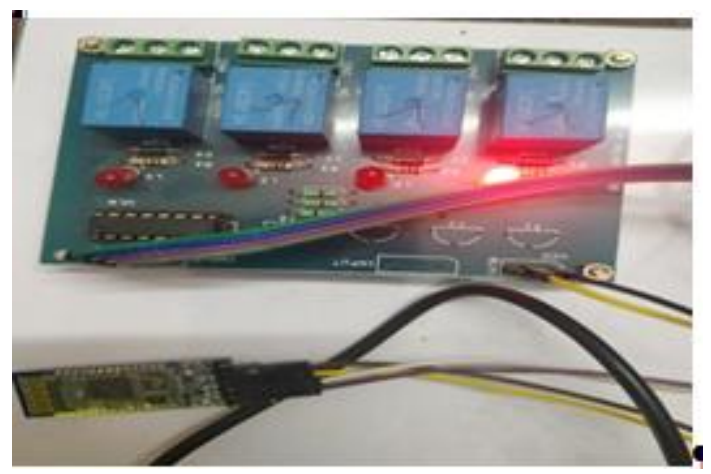

Fig.5. Relay Switching

In the figures 5 and 6 are the resultant of the gesture based automation technique. Here the glove is the transmitter that transmits a character based on the gesture made by the user. The character is received by the automation setup over Bluetooth. Based on the character received the respective relay is toggled.

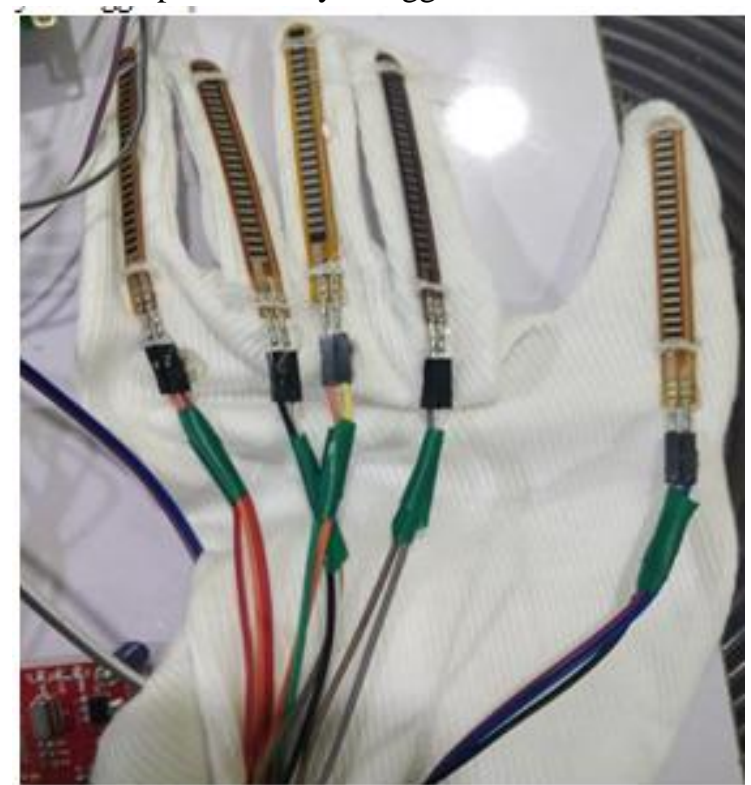

Fig.6. Glove Setup

Table-I: Gesture for Relay switching

\begin{tabular}{|c|l|l|l|l|l|}
\hline $\begin{array}{c}\text { Gest } \\
\text { ure no }\end{array}$ & $\begin{array}{l}\text { Flex } \\
\text { sensor } \\
1\end{array}$ & $\begin{array}{l}\text { Flex } \\
\text { sensor } \\
2\end{array}$ & $\begin{array}{l}\text { Flex } \\
\text { sensor } \\
3\end{array}$ & $\begin{array}{l}\text { Flex } \\
\text { sensor } \\
4\end{array}$ & $\begin{array}{l}\text { Fle } \\
\text { sensor } \\
5\end{array}$ \\
\hline 1 & 1 & 0 & 0 & 0 & 0 \\
\hline 2 & 0 & 1 & 0 & 0 & 0 \\
\hline 3 & 0 & 0 & 1 & 0 & 1 \\
\hline 4 & 0 & 0 & 0 & 1 & 0 \\
\hline
\end{tabular}

\section{GESTURE TO SPEECH}

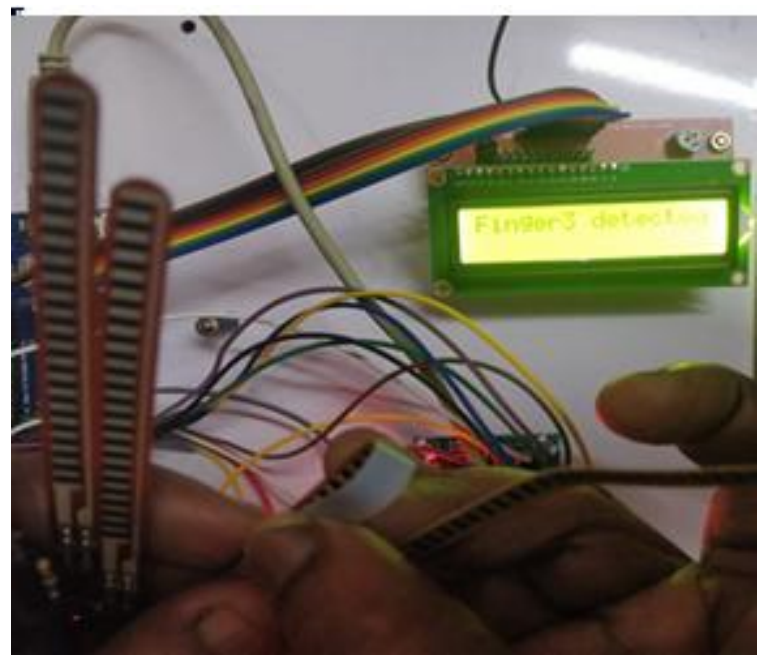

Fig.7. Gesture to speech

Figure 7 is the result of the gesture to speech, five flex sensor resistors that are used to recognise the gesture made by the person and Sunrom TTS module which converts text to speech here the speaker will be the output device through

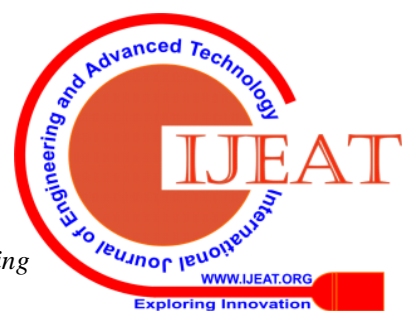


which audios for respective gestures will be played. In this project we convert fifteen gestures to speech. The Arduino Uno is programmed such a way that for each gesture there will be a text encoded to it. When a person replicates the gesture the respective text will be converted speech through the TTS module and is played out loud using the speaker. The TTS module works based on simple English phonemes therefore it does not have any limitation of words it can speak. The gesture to speech setup is mostly a standalone system does not depend on any smart devices like mobile or internet making it more practical. The usage of this TTS module makes the whole system portable and sleek and user friendly.

Table-II: Gesture table for speech

\begin{tabular}{|c|l|l|l|l|l|}
\hline $\begin{array}{r}\text { Gest } \\
\text { ure no }\end{array}$ & $\begin{array}{l}\text { Fle } \\
\text { sensor } \\
1\end{array}$ & $\begin{array}{l}\text { Fle } \\
\text { sensor }\end{array}$ & $\begin{array}{l}\text { Fle } \\
\text { x }\end{array}$ & $\begin{array}{l}\text { Fle } \\
\text { sensor }\end{array}$ & $\begin{array}{l}\text { Fle } \\
\text { sensor } \\
4\end{array}$ \\
\hline 1 & 1 & 0 & 0 & 0 & $\begin{array}{l}\text { sensor } \\
5\end{array}$ \\
\hline 2 & 0 & 1 & 0 & 0 & 0 \\
\hline 3 & 0 & 0 & 1 & 0 & 1 \\
\hline 4 & 0 & 0 & 0 & 1 & 0 \\
\hline 5 & 0 & 0 & 0 & 0 & 1 \\
\hline 6 & 1 & 1 & 0 & 0 & 0 \\
\hline 7 & 0 & 1 & 1 & 0 & 0 \\
\hline 8 & 0 & 0 & 1 & 1 & 0 \\
\hline 9 & 0 & 0 & 0 & 1 & 1 \\
\hline 10 & 1 & 0 & 0 & 0 & 1 \\
\hline
\end{tabular}

\section{FUTURE WORK}

The system can further be developed into a sign language translator and can also be converted into a tracker with which the user can be easily tracked if they are lost. This could be very helpful for people affected by cerebral palsy.The GPS helps in tracking the live location of the user. The GPS uses triangulation method for tracking the user's location. If the user is seemed to be lost, the user can simply make a gesture to toggle GPS mode. Then the GSM module helps in sending an alert message to the user's family members indicating the user's location. This model can also be converted into sign language translator by storing predefined data in the raspberry Pi's memory and with the help of Flex sensors the signs made by the user can be recognized and converted into speech. Which can help people who are deaf and mute to communicate with sign language

\section{REFERENCES}

1. Celestinepreetam, GirishRamakrishnan ,SujanKumar, Nagendra Krishnapura, “ Hand Talk Implementation of gesture recognizing glove” (2013).

2. Sakunthala vegunta,A.B Bhavani,M. Mallikarjun, "Gesture based Sensor device with GPS and GSM Technology for Dumb people" (2017).

3. Piyush Patil, Jayesh Praja "Implementation of a Real TimeCommunication System for Deaf People UsingInternet Of Things",(2017).

4. P.N Arathi, S. Arthika, S. Ponmithra, K. Srinivasan, V. Rukkumani "Gesture based Home Automation system" (2017).
5. Gurashish Singh, Alexander Nelson, Ryan Robucci, Chintan Patel, Nilanjan Banerjee, "Demo Abstract: Inviz: Low-power PersonalizedGesture Recognition Using Wearable TextileCapacitive Sensor Arrays"(2015)

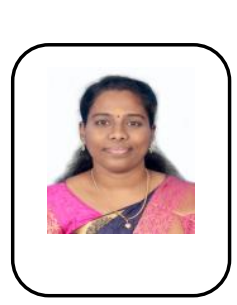

\section{AUTHORS PROFILE}

B.Ponkarthika, working as an Assistant Professor in the Department of Electrical and Electronics Engineering, Easwari Engineering College, Chennai, Tamil Nadu, India .She received her B.E degree in Electrical and Electronics Engineering from Saranathan College of Engineering, M.E. degree in Power Electronics and drives from Jerusalem College of Engineering, Anna University, Chennai, India. She has published over 13 Technical papers in National and International Conferences Proceedings/ Journals She has authored one book on Control Systems Engineering. Her research interests include resonant inverters for induction heating and intelligent controllers.

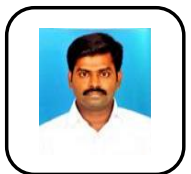

Dr.E.Kaliappan, working as Professor and Head of the Electrical and Electronics Engineering department in Easwari Engineering College, Ramapuram, Chennai, Tamil Nadu. He obtained his PhD. in Special Electrical Machines from Anna University; Chennai. He has more than 19 years of teaching experience and 10 years of research experience. He has published more than 30 papers in International and National journals and presented more than 50 papers in International and national conferences.

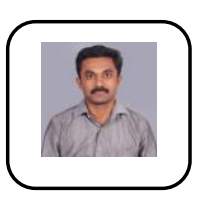

V.Vijeesh, working as an Assistant Professor in the Department of Electrical and Electronics Engineering, Easwari Engineering College, Chennai, Tamil Nadu, India .He received his B.E degree in Electrical and Electronics Engineering from Noorul Islam College of Engineering, M.E. degree in Power system engineering from Government College of Technology, Coimbatore, India. He has published over 10 Technical papers in National and International Conferences Proceedings/ Journals His research interests include Insulation testing and smart grid.

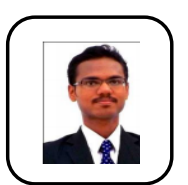

G.Vignesh, working as an Assistant Professor in the Department of Electrical and Electronics Engineering, Easwari Engineering College, Chennai, Tamil Nadu, India .He received his B.E degree in Electrical and Electronics Engineering from Saveetha Engineering College, M.E. degree in Power Electronics and drives from SKR Engineering College, Anna University, Chennai, India. He has also specialized in Clean Energy domain and has completed a course on Solar Energy through Edx from Delft University of Technology, Netherlands. His areas of interest include Power Electronics for Solar PV. Powe Conditioners of Wind Turbines, Energy Management and Energy Efficiency 